\title{
Structure characterization of metal oxide clusters by vibrational spectroscopy: possibilities and prospects $\nmid \ddagger$
}

\author{
Knut R. Asmis* \\ Received 9th March 2012, Accepted 12th April 2012 \\ DOI: $10.1039 / \mathrm{c} 2 \mathrm{cp} 40762 \mathrm{k}$
}

This article summarizes the methodological progress that has been made in the vibrational spectroscopy of isolated polynuclear metal oxide clusters, with particular emphasis on free electron laser-based infrared action spectroscopy of gas phase clusters, over the last decade. The possibilities, limitations and prospects of the various experimental approaches are discussed using representative examples from pivotal studies in the field.

\section{Introduction}

Due to their structural variability, redox activity and other interesting properties metal oxide nanomaterials ${ }^{1}$ are playing an increasingly important role in diverse areas of science and technology like heterogeneous catalysis, ${ }^{2}$ optoelectronic nanosensors, ${ }^{3}$ coatings, magnetic materials in biomedical applications ${ }^{4}$ or fuel cells. ${ }^{5}$ However, it remains difficult to gain insight into the structure and functionality of these particles with atomic resolution. This motivates experimental

Fritz-Haber-Institut der Max-Planck-Gesellschaft, Faradayweg 4-6, D-14195 Berlin, Germany.E-mail: asmis@fhi-berlin.mpg.de;

Fax: + 4930 8413-5603; Tel: + 4930 8413-5735

$\dagger$ This article is dedicated to Prof. Dr Drs h. c. Ludger Wöste on the occasion of his 65 th birthday.

$\ddagger$ This article is part of the themed issue "Structure and reactivity of small particles: from clusters to aerosols".

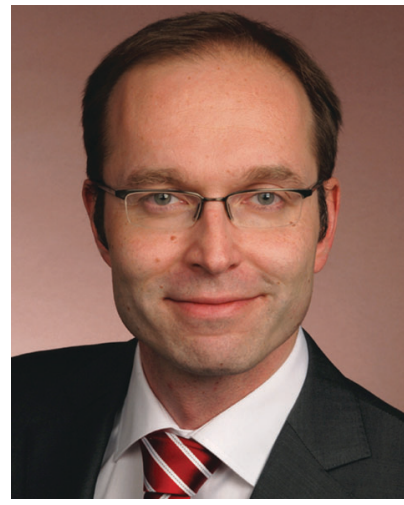

Knut R. Asmis
Knut R. Asmis received his $\mathrm{Dr}$ rer. nat. in Physical Chemistry from the Université de Fribourg, Switzerland, in 1996. After his Postdoctoral fellowship at the University of California, Berkeley, he moved to the Freie Universität Berlin in 1999 and earned his Habilitation in Experimental Physics in 2006. Since 2005 he has been a Research Group Leader and since 2009 a Permanent Staff Scientist at the Fritz-HaberInstitut of the Max-PlanckGesellschaft in Berlin, where he continues to develop new techniques to study the vibrational spectroscopy of gas phase clusters, with emphasis on hydrogen bonding, ion and electron solvation as well as the structure, dynamics and reactivity of metal oxide clusters. studies on isolated metal oxide clusters of well-defined composition. The reduced complexity, due to the absence of perturbing interactions with an environment or support, combined with the high sensitivity and selectivity obtainable, for example, in gas phase experiments, allows systematically characterizing the interplay between composition, cluster size, structure and shape, on one side, and the intrinsic physical and chemical cluster properties, on the other hand, at the molecular level. In this context, gas phase cluster studies have proven particularly useful in developing a conceptual framework for understanding more complex processes. ${ }^{6}$

A more fundamental motivation for performing experiments on isolated clusters lies in our curiosity in studying this peculiar state of matter. Clusters containing a few up to a few tens of atoms are not simply intermediates between isolated atoms/molecules and macroscopic particles, but rather their properties lie in the non-scalable regime, i.e., they cannot be extrapolated from the properties of larger nanoparticles. ${ }^{7}$ The unique possibility of studying the evolution of properties as a function of size, one atom at a time, under well-defined conditions makes gas phase experiments on size-selected clusters so appealing. However, many of the high resolution characterization techniques used for condensed phase samples cannot be applied to the study of size-selected gas phase clusters, because the attainable number densities are simply too low. In direct absorption spectroscopy, for example, the attenuation in the transmitted light intensity is measured; as the number density is lowered it becomes increasingly difficult to detect these changes. ${ }^{8}$ Hence, the structural characterization of gas phase clusters requires the development of alternative experimental approaches, methods, in which the absorption of photons is measured indirectly by detecting their action in the molecule. ${ }^{9}$

Performing experiments on gas phase metal oxide clusters also allows testing and benchmarking the predictions from quantum chemical methods. Currently, the structural characterization of gas phase clusters (with more than just a few atoms) using action spectroscopy is typically indirect; measured properties 
are compared to calculated properties for a given structure predicted by quantum chemistry. Since it remains difficult to unambiguously identify the global minimum energy structure on a complex potential energy surface, generally both, experiment and theory, are required for a reliable structure assignment. Furthermore, small and medium-sized clusters containing up to a few tens of atoms can be treated with high-level quantum chemistry methods. A comparison between calculated and experimental values for properties like vibrational frequencies, electron detachment energies or binding energies then serves as a sensitive benchmark for testing the performance of different computational models; a prerequisite for judging their accuracy and also their applicability to larger, more complex systems.

Experimental studies on gas phase metal oxide clusters have mainly focused on the characterization of the relationship between cluster composition and reactivity using various mass spectrometric approaches (see for example ref. 10 and references therein). Complementary information on the cluster composition and stability can be gained from UV/VIS photodissociation studies $^{11}$ on charged, as well as photoionization studies ${ }^{12}$ on neutral clusters. Experimental information regarding the cluster shape and structure has been more difficult to come by and typically requires a spectroscopic approach. Only a few spectroscopic techniques have been applied to the systematic structural characterization of isolated metal oxide clusters of which gas phase infrared (IR) action spectroscopy (combined with quantum chemistry) has emerged as the technique which arguably has allowed for the most detailed indirect structural characterization of small and medium-sized clusters to date.

The goal of the present article is two-fold, to summarize the methodological progress that has been made in the field of vibrational spectroscopy on isolated metal oxide clusters over the last decade from the perspective of a spectroscopist and to highlight a few pivotal studies that exemplify this progress and demonstrate the possibilities (as well as the limitations) of the different experimental approaches. This article focuses primarily on the experimental work related to polynuclear metal oxide clusters, i.e., on oxide clusters containing at least two metal atoms or more, and is not intended as a comprehensive review of the field. This perspective article begins with an overview of the spectroscopic methods applied to the structural characterization of polynuclear metal oxide clusters, followed by a more detailed description of the different variants of gas phase IR action spectroscopy, and ends with an outlook on potential methodological developments.

\section{Spectroscopic methods}

The rotational, vibrational and electronic spectroscopy of diatomic metal oxide species, both neutral and ionic, has been studied in great detail. A variety of high resolution spectroscopic techniques that allow for a direct structural characterization have also been applied to triatomic systems, for example, resonance enhanced UV/VIS multiphoton ionization, laser-induced fluorescence (LIF) and pulsed-field ionization zero electron kinetic energy (ZEKE) photoelectron spectroscopy. ${ }^{13-16,17}$ Significantly less is known concerning the structures of larger polynuclear metal oxide clusters, due to several reasons. High resolution techniques require high sample concentrations, which are increasingly difficult to obtain with increasing cluster size. While mononuclear metal oxide species can be prepared rather selectively by thermal evaporation, larger clusters are typically formed by laser vaporization, characterized by a broad size distribution. With increasing cluster size these techniques run into the problem of spectral congestion due to the complex nature of rovibronic transitions in polyatomic species and to the presence of multiple absorbing species. Other powerful structural characterization techniques, like trapped ion electron diffraction ${ }^{18}$ and IR/UV ion dip spectroscopy, ${ }^{19}$ have not yet been applied to metal oxide clusters. Trapped ion electron diffraction works best for quasi-ordered clusters of heavier nuclei (e.g. metal clusters), while IR/UV ion dip spectroscopy typically requires knowledge of the electronically excited states of the system.

\subsection{Matrix isolation infrared spectroscopy}

Matrix isolation studies can overcome some of these limitations, because species can be accumulated over many minutes or even hours in an inert matrix. Hence, matrix-isolation infrared (MI-IR) absorption spectroscopy $y^{20,21}$ has evolved as a very useful technique to characterize the structure of smaller polynuclear metal oxide clusters (see Table 1). The structural characterization of larger clusters requires size-selectivity. Wöste and coworkers $^{22}$ pioneered the optical absorption spectroscopy of matrix-isolated mass-selected clusters, but this technique has been difficult to extend to the IR region, where absorption cross sections are significantly smaller. ${ }^{21}$ To date, the only vibrational spectra reported for mass-selected metalcontaining clusters in rare gas matrices are Raman measurements on pure metal clusters. ${ }^{23}$ Matrix LIF studies ${ }^{21}$ have not been widely used, in part because of the loss of any rotational resolution when matrix-isolated species are probed.

MI-IR studies on transition metal oxides have recently been reviewed by Gong, Zhou and Andrews ${ }^{24}$ and focus mainly on mono- and bi-nuclear metal oxide species. Notable exceptions are the $\mathrm{IR}^{25,26}$ and $\operatorname{Raman}^{26}$ spectra of matrix-isolated $\mathrm{V}_{4} \mathrm{O}_{10}$ shown in Fig. 1. ${ }^{25,26}$ Heating of vanadium pentoxide produces predominantly a single cluster size in the vapor phase, namely $\mathrm{V}_{4} \mathrm{O}_{10}$, which can then be accumulated selectively in an inert matrix and used for absorption and Raman scattering measurements. The two complementary spectra shown in Fig. 1 do not only allow for an unambiguous experimental confirmation of the tetrahedral structure of neutral $\mathrm{V}_{4} \mathrm{O}_{10}$, but also contain information on the different sites $\mathrm{V}_{4} \mathrm{O}_{10}$ occupies within the matrix. ${ }^{27}$

\subsection{Anion photoelectron spectroscopy}

In general, the structural characterization of clusters of this and larger sizes requires size-selectivity. The size-selective formation of $\mathrm{V}_{4} \mathrm{O}_{10}$ by thermal heating is exceptional. Currently, the most widely used size-selective technique for studying the spectroscopy of metal oxide clusters (see Table 1) is anion photoelectron spectroscopy (APES). Mass-selected cluster anions are irradiated by a fixed frequency UV/VIS laser and the photoelectron yield is recorded as a function of the photoelectron kinetic energy. Like almost all size-selective gas phase cluster approaches it belongs to the class of action spectroscopy, 
Table 1 Summary of experimental studies on the vibrational spectroscopy of isolated polynuclear metal oxide clusters $\mathrm{M}_{m} \mathrm{O}_{n}{ }^{+/ 0 /-}(m>1$ and $n>0)$

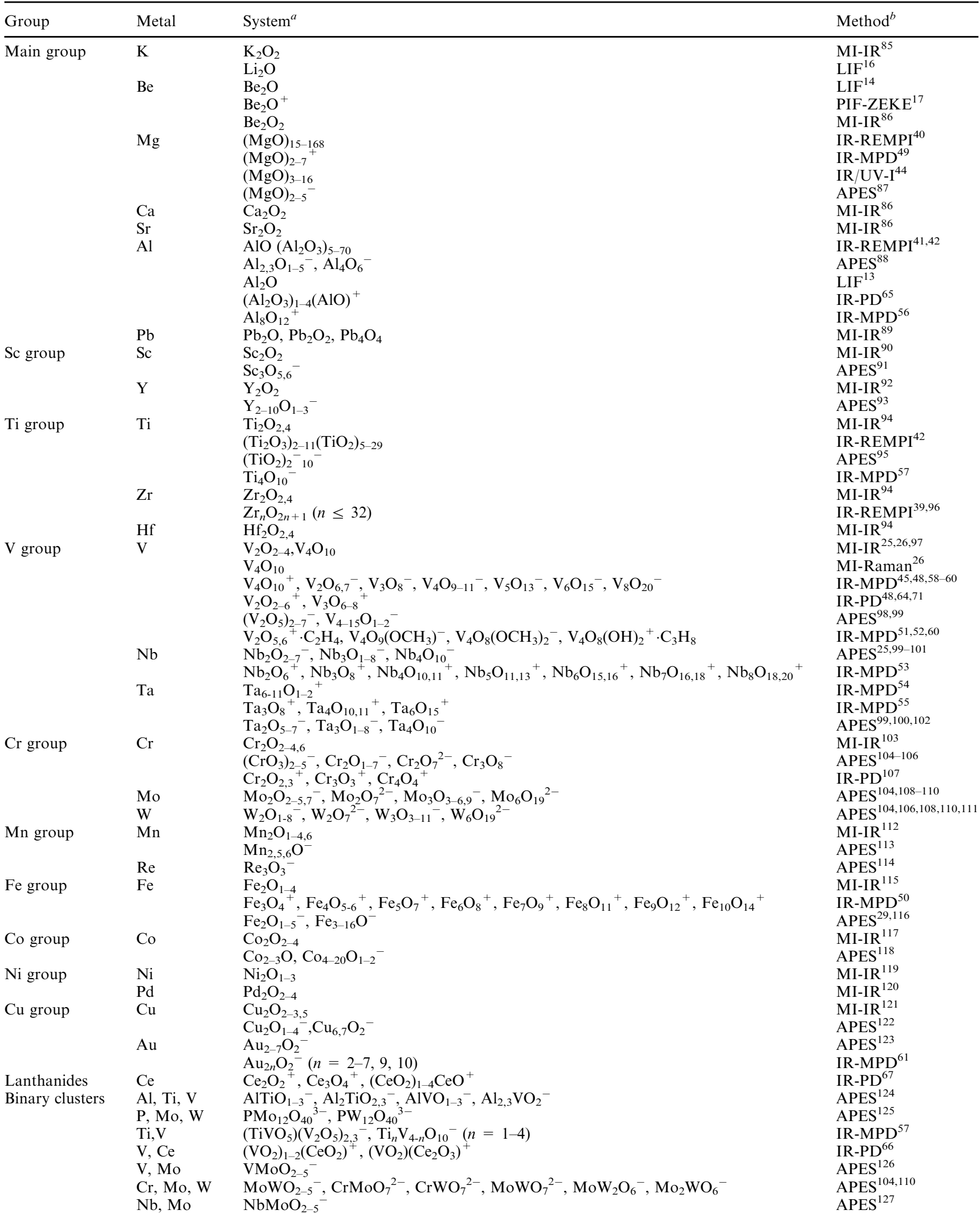

${ }^{a}$ The messenger species (rare gas atom or atoms) is omitted for the IR-PD measurements. ${ }^{b}$ Spectroscopic methods: matrix-isolation infrared (MI-IR) and Raman (MI-Raman), laser-induced fluorescence (LIF), pulsed-field ionization zero electron kinetic energy photoelectron (PIF-ZEKE), infrared resonance enhanced multiple photon ionization (IR-REMPI), infrared multiple photon dissociation (IR-MPD), IR/UV two-color ionization (IR/UV-I), and anion photoelectron spectroscopy (APES), as well as infrared photodissociation (IR-PD) spectroscopy of cluster ion-rare gas atom complexes. 

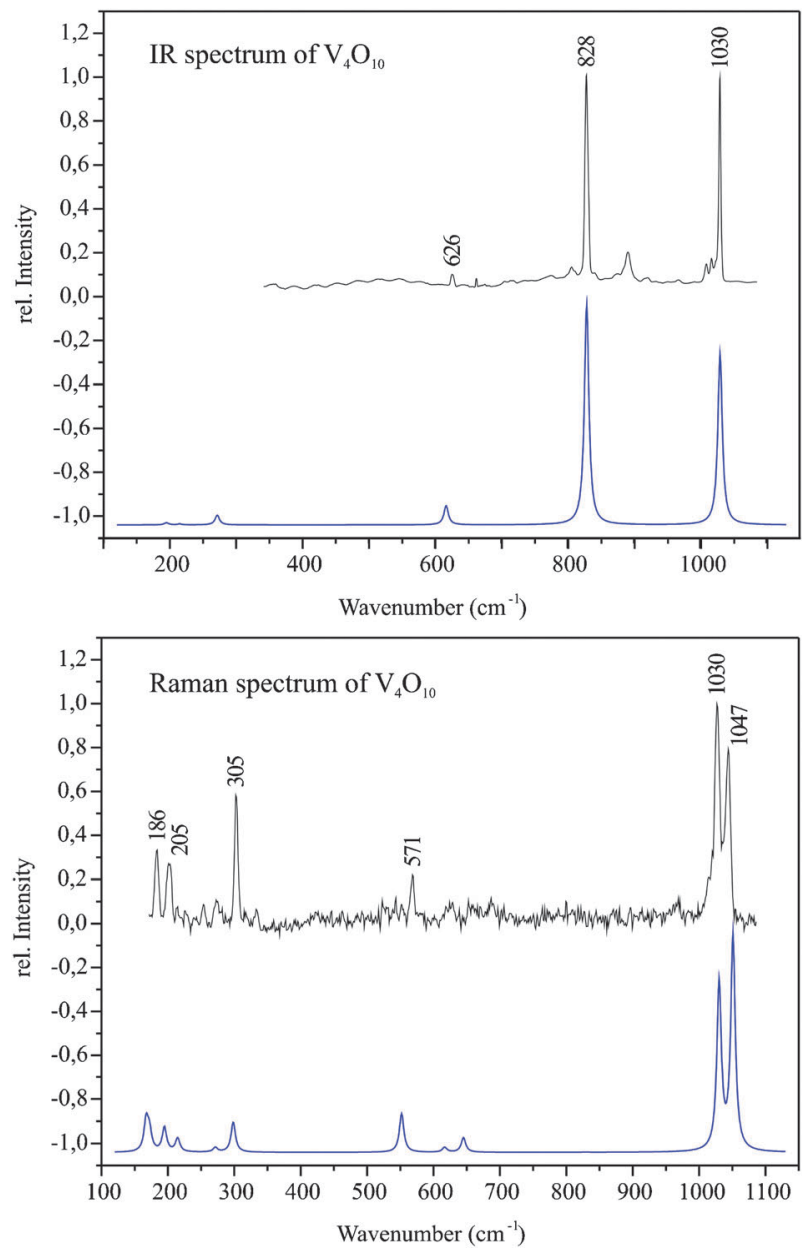

Fig. 1 IR absorption and Raman spectra of matrix-isolated $\mathrm{V}_{4} \mathrm{O}_{10} \cdot{ }^{26}$ Traces (from top to bottom): experimental MI-IR spectrum $\left(\mathrm{N}_{2}\right.$ matrix, $T=10 \mathrm{~K}$ ), calculated IR absorption spectrum, experimental MI-Raman spectrum $\left(\mathrm{N}_{2}\right.$ matrix, $T=10 \mathrm{~K}$, laser: $\left.\lambda=514.5 \mathrm{~nm}, P=250 \mathrm{~mW}\right)$, and calculated Raman spectrum.

i.e., it relies on detecting an action subsequent to the absorption of a photon, in this particular case photoelectron detachment:

$$
\mathrm{M}_{m} \mathrm{O}_{n}^{-}+h \nu \rightarrow \mathrm{M}_{m} \mathrm{O}_{n}+\mathrm{e}^{-} .
$$

Experimentally, APES is relatively simple to implement. It does not require a tunable laser source and commercially available nanosecond lasers produce sufficiently energetic photons to photodetach most anions, even metal oxide anions, which are among the anions with the highest electron affinities (EAs). In contrast, photoionization of neutral clusters, for example, typically requires higher energies, and adequate laser sources are often a limiting factor (see Section 3.2).

APES was initially applied to the study of the diatomic $\mathrm{FeO}^{-}$in 1977 by Engelking and Lineberger ${ }^{28}$ and to iron oxide cluster anions $^{29}$ in 1996 by Wang and coworkers. APES studies on transition metal oxide clusters have been recently reviewed by Zhai and Wang. ${ }^{30}$ As a representative example, the APE spectra of $\mathrm{Fe}_{2} \mathrm{O}_{n}{ }^{-}$with $n=1-5$ are shown in Fig. 2. The adiabatic electron affinity (EA) of the neutral molecules can be determined fairly accurately from the binding energy of the $\nu=0$ vibrational feature when vibrational structure is

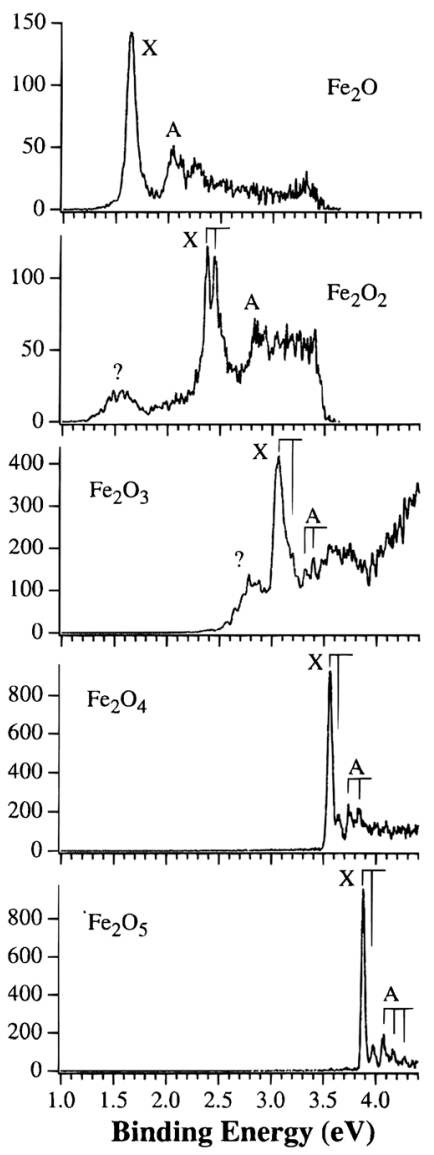

Fig. 2 Photoelectron spectra of $\mathrm{Fe}_{2} \mathrm{O}_{y}{ }^{-}(y=1-5){ }^{29}$ The spectra of $\mathrm{Fe}_{2} \mathrm{O}^{-}$and $\mathrm{Fe}_{2} \mathrm{O}_{2}{ }^{-}$are taken at $3.49 \mathrm{eV}$ photon energy while those of the higher oxides are taken at $4.66 \mathrm{eV}$. The vertical lines indicate the resolved vibrational structures. " $\mathrm{X}$ " represents the ground state of the neutrals and "A" represents the excited states. Reprinted with permission from ref. 29. Copyright (2012) American Chemical Society.

resolved for the ground state (labeled by an ' $\mathrm{X}$ ' in Fig. 2). ${ }^{29}$ From this information concerning the oxidation state and bonding properties can be derived. The near linear increase in the EA with $n$ in Fig. 2 suggests a sequential oxidation behavior. The resolved progressions, indicated by the vertical lines in Fig. 2, reflect the vibrational excitation upon photodetachment and allow insight into the geometric structure of the neutral cluster. Since APES is sensitive to the difference in geometry between the anionic and neutral clusters, geometric predictions for both charge states (neutral as well as anion) can be made in favorable cases. Compared to MI-IR spectroscopy (see Section 2.1) and IR action spectroscopy, discussed in the next section, the vibrational information obtained from APES is not as detailed, due to the modest energy resolution, but it can be complementary to that obtained from IR spectroscopy due to the different selection rules for photodetachment $v s$. IR photoabsorption.

\section{Infrared action spectroscopy}

The most detailed structural information on polynuclear metal oxide clusters is currently gained from IR action spectroscopy. ${ }^{9,31,32}$ There are several variants of this technique, but they all have in common that they require an intense and tunable 


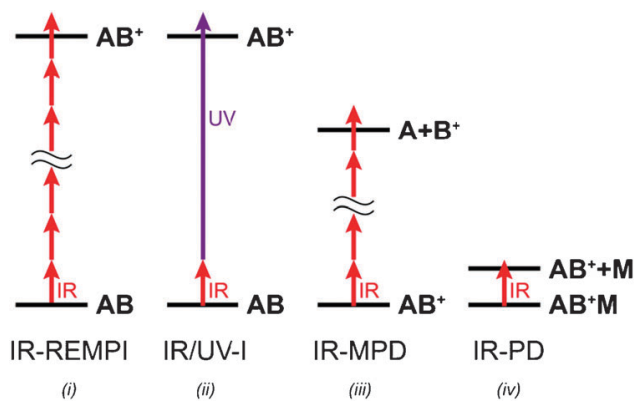

Fig. 3 Schematic of four experimental techniques for probing the IR action spectroscopy of gas phase metal oxide clusters: IR resonance enhanced multiple photon ionization (IR-REMPI), IR/UV two-color ionization (IR/UV-I), IR multiple photon dissociation (IR-MPD), and IR photodissociation (IR-PD) spectroscopy of cluster ion-rare gas atom complexes.

IR laser source. ${ }^{9,33,34}$ The IR-active fundamental vibrational modes of metal oxide clusters lie below $1700 \mathrm{~cm}^{-1}$ with the more intense $\mathrm{M}-\mathrm{O}$ stretching and bending transitions typically found in-between $300-1200 \mathrm{~cm}^{-1}$. This spectral region only became fully accessible to gas phase experiments on clusters with the introduction of IR free electron lasers (IR-FELs) to molecular spectroscopy in $1996 .{ }^{35}$ Indeed, advances in the IR spectroscopy of polynuclear metal oxide clusters are closely related to the development of action spectroscopy using IR-FELs, in general.

Four different types of IR action spectroscopy, namely infrared resonant enhanced multiple photon ionization (IR-REMPI), IR/UV two-color ionization (IR/UV-I), infrared multiple photon dissociation (IR-MPD) and infrared photodissociation (IR-PD) spectroscopy of messenger-tagged clusters, have been successfully applied to the study of polynuclear metal oxide clusters. They are schematically shown in Fig. 3. Conceptually, they can be divided into experiments on neutral (IR-REMPI and IR/UV-I) and charged (IR-MPD and IR-PD) clusters. Typically, experiments on neutral clusters are performed on cluster distributions and exploit a change in charge state (photoionization), while the experiments on charged clusters can, but do not necessarily need to, take advantage of massselection prior to IR irradiation and involve a change in mass (photodissociation). All four schemes have in common that a vibrational spectrum is obtained by recording a mass-selected yield as a function of the IR radiation wavelength. This IR action spectrum is generally not identical to the (linear) IR absorption spectrum, but can reflect it rather well, depending on the particular technique used and the size and nature of the cluster studied.

\subsection{Infrared resonant enhanced multiple photon ionization}

In IR-REMPI spectroscopy, ${ }^{36}$ scheme (i) in Fig. 3, a beam of neutral clusters is irradiated by intense and tunable IR radiation. It was one of the first techniques used in combination with IR-FELs. ${ }^{37}$ When the wavelength of the IR radiation is resonant with a vibrational transition the clusters are heated. Eventually, the clusters may lose an electron, similar to the process of thermionic emission observed for hot surfaces:

$$
\mathrm{AB} \stackrel{h v_{\text {II }}}{\longrightarrow} \mathrm{AB}^{*} \stackrel{h v_{\text {IR }}}{\longrightarrow} \ldots \stackrel{h v_{\text {IR }}}{\longrightarrow} \mathrm{AB}^{+}+\mathrm{e}^{-} .
$$

Typical ionization energies of metal oxide clusters lie in-between 5 and $10 \mathrm{eV}$ and therefore up to many hundreds of IR photons need to be absorbed to induce ionization. This technique relies on the efficient absorption of many IR photons via the mechanism of infrared multiple photon excitation, which is described in detail elsewhere. ${ }^{36,38}$ Briefly, infrared multiple photon excitation is not a coherent multiphoton absorption process in a single vibrational ladder, but rather involves the non-coherent, sequential absorption of multiple single photons. Anharmonicities play a central role, because they introduce a coupling mechanism between different vibrational modes, allowing for internal vibrational redistribution (IVR) of the energy. In the limit of fast IVR, each photoabsorption event is followed by IVR, effectively "de-exciting" the IR-excited transition. The rate of photon absorption is then limited by the IVR rate, the properties of the light source, as well as the (cross-) anharmonicities in the molecule.

Historically, the first gas phase method used to characterize the vibrational action spectroscopy of metal oxide clusters was IR-REMPI, initially applied to the study of neutral zirconium oxide clusters. ${ }^{39} \mathrm{Zr}_{n} \mathrm{O}_{2 n-1}$ clusters are amenable to thermionic electron emission, because they are characterized by high binding energies and, compared to $\mathrm{Zr}_{n} \mathrm{O}_{2 n}$ clusters, low ionization energies. The IR-REMPI spectra of $\mathrm{Zr}_{n} \mathrm{O}_{2 n-1}$ clusters (see Fig. 4) show one or two broad features in-between 500 and $800 \mathrm{~cm}^{-1}$, suggesting bulk-like structures containing 4-membered $\mathrm{ZrO}_{2}$ rings. ${ }^{39}$ The width of the IR-REMPI features is (in part) a result of the relatively high fluence, broad bandwidth IR-FEL laser pulses required, to ionize the neutral clusters. In addition, cluster ionization, dissociation, and ionization followed by dissociation are all feasible channels

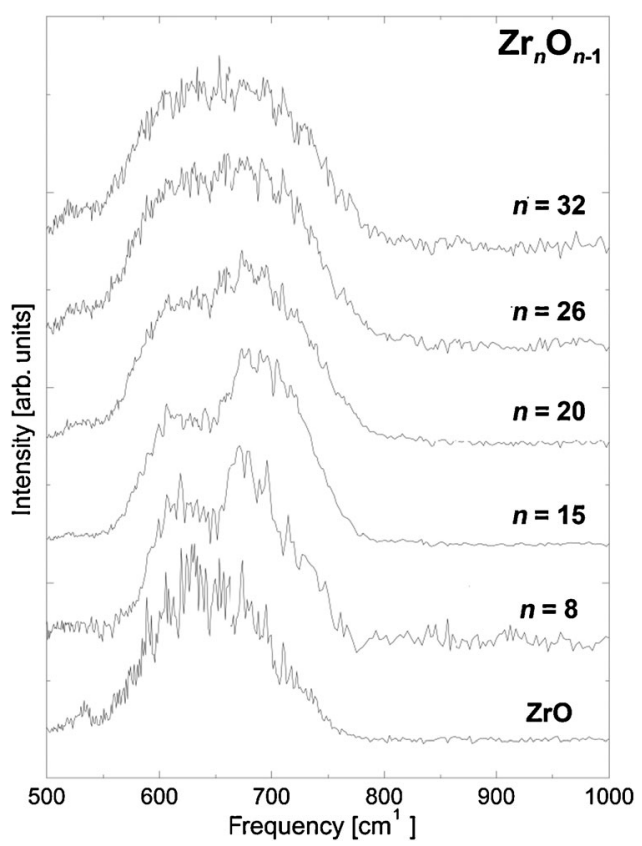

Fig. 4 IR-REMPI spectra of $\mathrm{Zr}_{n} \mathrm{O}_{2 n-1}$ clusters. ${ }^{39}$ The neutral clusters can be efficiently excited with IR radiation to internal energies high enough $(\sim 6 \mathrm{eV})$ for the thermionic emission of an electron. The lowest trace corresponds to the signal of $\mathrm{ZrO}^{+}$, which is formed as a fragment. Adapted from ref. 39, Copyright (2012), with permission from Elsevier. 
and require comparable energies for these particular systems, complicating the interpretation of the experimental spectra. A structural assignment to individual cluster structures is generally not possible. Nonetheless, the pioneering IR-REMPI experiments allowed identifying the size-dependent trends in the IR spectra of neutral $\mathrm{Zr}^{39} \mathrm{Mg}^{40} \mathrm{Al}^{41,42}$ and $\mathrm{Ti}^{36,42}$ oxide clusters with up to several hundred atoms, paving the way for the subsequently applied approaches.

\subsection{IR/UV two-color ionization}

More detailed vibrational information on neutral metal oxide clusters can be gained by performing IR/UV two-color ionization experiments (see scheme (ii) in Fig. 3). ${ }^{43,44}$ Following the resonant absorption of one (or a few) IR photon(s) from the tunable IR laser pulse, the remaining energy to overcome the ionization energy is supplied by the absorption of a single UV photon:

$$
\mathrm{AB} \stackrel{h v_{\mathrm{IR}}}{\longrightarrow} \mathrm{AB}^{*} \stackrel{h v_{\mathrm{UV}}}{\longrightarrow} \mathrm{AB}^{+}+\mathrm{e}^{-} .
$$

The wavelength of the UV laser is typically chosen such that no or little ionization is detected in the absence of the IR laser pulse. The advantage of IR/UV two-color ionization $v s$. IR-REMPI is obvious - by replacing the energy of many tens of IR photons with a single UV photon significantly fewer photons need to be absorbed. This allows the use of lower fluence, narrower bandwidth IR-FEL laser pulses, which lead to better resolved vibrational spectra and which are characterized by IR wavelength dependent ionization yields that are more closely related to linear IR absorption cross sections. In principle, the energy of the UV photon needs be adjusted individually for each type and size of the cluster. In practice, often a single UV photon energy can be used for a series of clusters with similar ionization energies. ${ }^{44}$

Recently, Haertelt et al. applied the IR/UV two-color ionization excitation scheme to the study of neutral $(\mathrm{MgO})_{n}$ clusters with $n=3-19$. To this end, they combined the tunable radiation from an IR-FEL $\left(200-1700 \mathrm{~cm}^{-1}\right)$ with the fixed frequency output of a $F_{2}$ laser $(7.87 \mathrm{eV})$. The ionization energies of smaller $(\mathrm{MgO})_{n}$ clusters are roughly $8 \mathrm{eV}$ and thus they are not efficiently ionized by the photons of the $\mathrm{F}_{2}$ laser only. However, when the IR-FEL pulse is applied prior $(\sim 30 \mu \mathrm{s})$ to the UV pulse and the photon energy of the IR-FEL is resonant with a vibrational transition, the clusters are efficiently internally heated, substantially increasing the ionization yield. As an example, the IR/UV two-color ionization spectra of $(\mathrm{MgO})_{3 n}$ clusters with $n=1-5$ are shown in Fig. 5. While the features observed in the IR/UV two-color ionization spectra are not as narrow as one would expect for linear absorption spectra, they are substantially narrower than comparable features in IR-REMPI spectra of $(\mathrm{MgO})_{n}$ clusters. ${ }^{40}$ This substantial increase in spectral resolution compared to IR-REMPI leads to a better comparability between experimental and simulated spectra and ultimately allows assigning individual structures. In Fig. 5 the hexagonal ring is identified as the fundamental building block for smaller $(\mathrm{MgO})_{3 n}$ clusters, which exhibit structures very different from the geometry of the simple cubic $\mathrm{MgO}$ bulk phase.

In summary, the IR/UV two-color ionization scheme is generally applicable and can be used to measure cluster-size

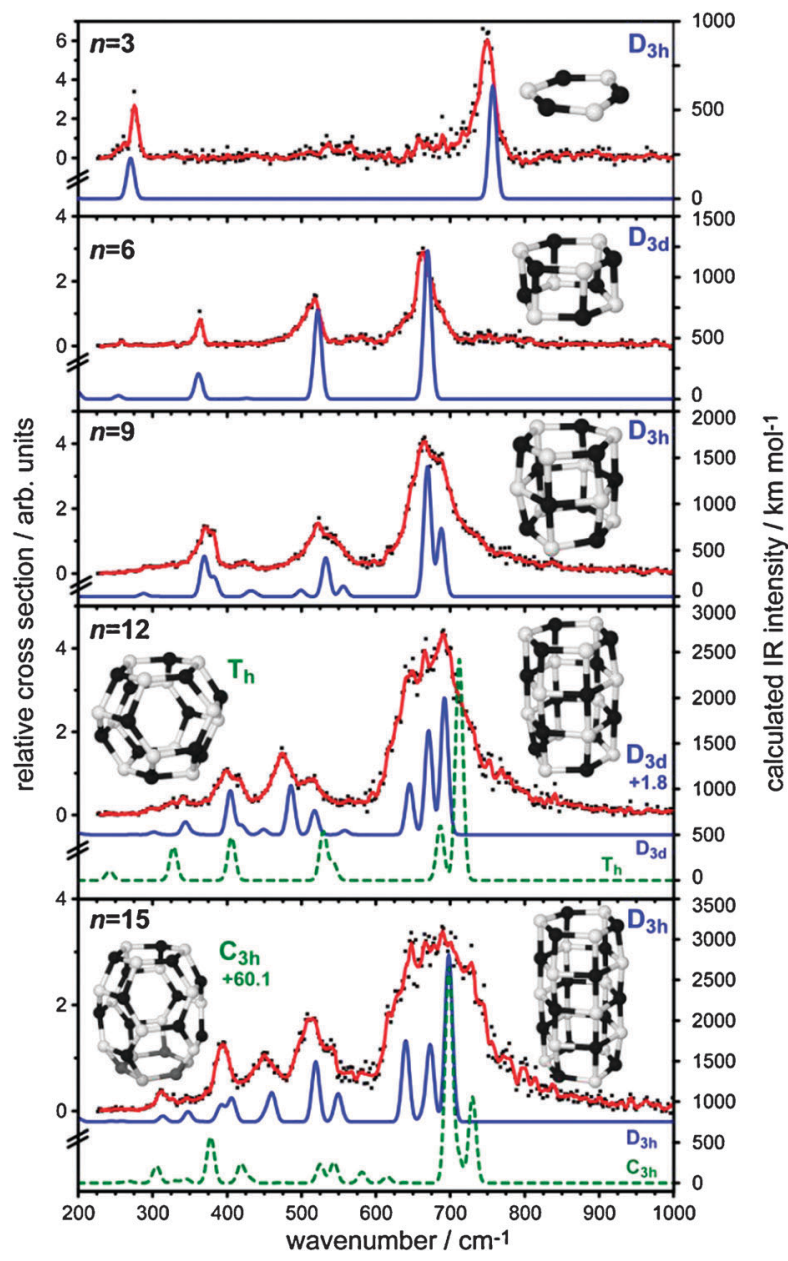

Fig. 5 IR/UV two-color ionization spectra of $\left({ }^{26} \mathrm{MgO}\right)_{3 n}$ clusters with $n=1-5$ and calculated linear absorption spectra (blue and green traces) ${ }^{44}$ The measured data points are shown as dots and a five-pointrunning average (solid red line) is added to guide the eye. Some of the theoretical spectra are vertically shifted for clarity. Relative energies of different isomers are given in $\mathrm{kJ} \mathrm{mol}^{-1}$. Adapted from ref. 44, Copyright (2012), with permission from Royal Society of Chemistry.

specific vibrational action spectra of neutral metal oxide clusters. The investigation of oxygen-rich metal oxides with typical ionization energies larger than $8 \mathrm{eV}$ remains difficult. This technique is currently limited by the availability of UV laser sources and will greatly profit from advances in the development of tunable vacuum UV sources.

\subsection{Infrared multiple photon dissociation}

The first IR technique applied to the study of mass-selected polyatomic metal oxide ions was IR-MPD in $2002 .{ }^{45}$ IR-MPD (see scheme (iii) in Fig. 3) for charged clusters ${ }^{46,47}$ is similar to IR-REMPI for neutral clusters in that it exploits the same infrared multiple photon excitation process, but instead of ionizing a neutral species a charged species is dissociated and a change in mass is eventually detected. Typically, photodissociation thresholds of cluster ions are lower than ionization thresholds for neutral clusters and therefore the restrictions on the IR-FEL pulse parameters imposed by the need for efficient infrared multiple photon excitation are significantly relaxed 
compared to those in IR-REMPI experiments, leading to better resolved IR action spectra.

Similar to IR-REMPI (see Section 3.1), intense and tunable IR radiation is used to resonantly heat the clusters in a sequential incoherent absorption process,

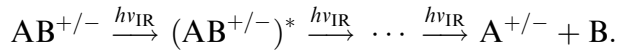

Only when the IR laser is resonant with a fundamental vibrational transition the initially vibrationally cold $\mathrm{AB}^{+/-}$ can start absorbing photons. Photodissociation techniques have the advantage that fragment ions can be detected backgroundfree and with nearly $100 \%$ efficiency. Furthermore, charged clusters can be manipulated easier than neutral clusters. Parent ions can be mass-selected prior to IR-irradiation using a mass filter, avoiding cross-talk between photodissociation channels of different parent ions leading to fragment ions of the same mass. Measurements without mass-selection prior to IR irradiation, on the other hand, have the advantage that complete cluster size distributions can be sampled at once. Temperaturecontrolled ion traps can be used to accumulate and thermalize the cluster ions. ${ }^{33,48}$ IR-MPD experiments have been performed on magnesium, ${ }^{49}$ iron $^{50}{ }^{5}$ vanadium, ${ }^{45,51,52}$ niobium $^{53}$ and tantalum ${ }^{54,55}$ oxide cations, and aluminium, ${ }^{56}$ titanium, ${ }^{57}$ vanadium, ${ }^{58-60}$ and gold $^{61}$ oxide anions, as well as mixed vanadium-titanium oxide anions ${ }^{57}$ (see Table 1 ).

As a representative example, mass-selective IR-MPD spectra of the binary metal oxide anions $\left(\mathrm{V}_{2} \mathrm{O}_{5}\right)_{1-3}\left(\mathrm{VTiO}_{5}\right)^{-}$, measured from 560 to $1085 \mathrm{~cm}^{-1}$, are shown in Fig. $6{ }^{57} \mathrm{Ti}$ and $\mathrm{V}$ were chosen in this study, because they are neighboring elements in the period table with $[\mathrm{Ar}] 3 \mathrm{~d}^{2} 4 \mathrm{~s}^{2}$ and $[\mathrm{Ar}] 3 \mathrm{~d}^{3} 4 \mathrm{~s}^{2}$ electron configurations, respectively - their electronic structure differs by a

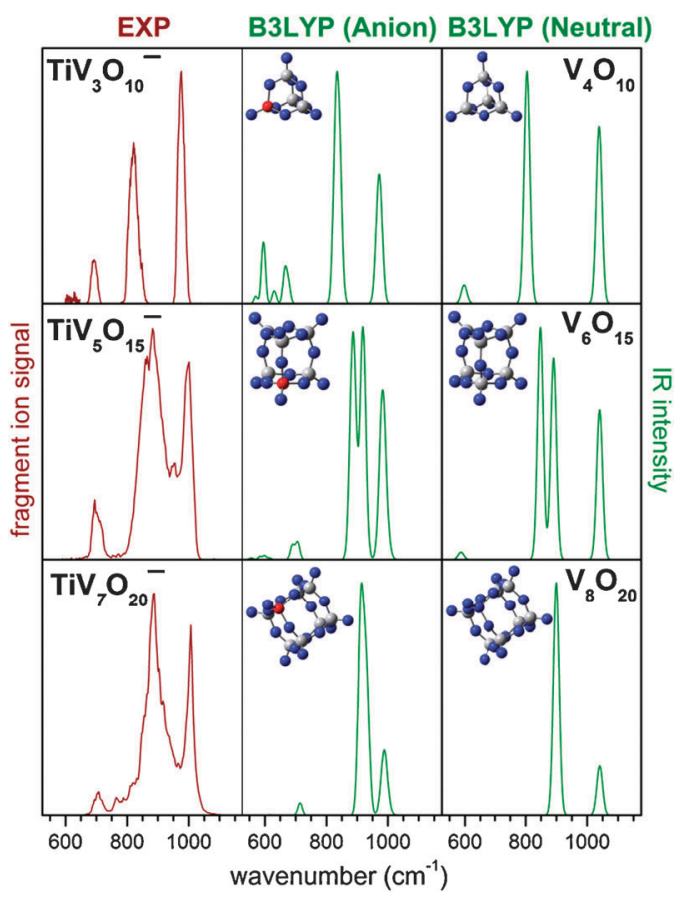

Fig. 6 Experimental IR-MPD (left) and simulated linear absorption spectra (center) of monosubstituted $\left(\mathrm{V}_{2} \mathrm{O}_{5}\right)_{n-1}\left(\mathrm{VTiO}_{5}\right)^{-}$anions, of the isoelectronic $\mathrm{V}_{2 n} \mathrm{O}_{5 n}{ }^{-}$anions, and of the neutral $\mathrm{V}_{2 n} \mathrm{O}_{5 n}$ clusters with $n=2-4 .{ }^{57}$ Geometries (O: blue, Ti: red and V: grey) are also shown. single valence electron. The singly substituted $\left(\mathrm{V}_{2} \mathrm{O}_{5}\right)_{1-3}\left(\mathrm{VTiO}_{5}\right)^{-}$ anions form polyhedral caged structures similar to those predicted for their isoelectronic counterparts, the neutral $\left(\mathrm{V}_{2} \mathrm{O}_{5}\right)_{n}$ clusters (see Fig. 6). ${ }^{57}$ Since mass-selecting neutral clusters is experimentally demanding and generally not feasible, this isomorphous substitution approach represents an elegant technique to indirectly probe the structure and vibrational spectroscopy of the corresponding isoelectronic neutral clusters, which are otherwise difficult to measure. The measured IR-MPD spectra (left column in Fig. 6) agree reasonably well with the simulated linear absorption spectra of the predicted lowest energy structures (center column in Fig. 6), supporting an assignment to the depicted structures. The remaining discrepancies regarding the relative intensities and band widths between experiment and simulation can only be removed, if the details of the sequential multiple photon absorption process are considered in the simulation. This can be done in principle, ${ }^{47}$ but requires knowledge of the cross-anharmonicities, which are generally not known experimentally and tedious to calculate.

\subsection{Infrared photodissociation of messenger-tagged clusters}

The dissociation of strongly bound metal oxide ions typically requires at least several eVs and therefore IR-MPD typically involves the absorption of many tens of IR photons. A useful approach to reduce the number of photons is the so-called messenger technique. ${ }^{31} \mathrm{~A}$ weakly-bound complex is formed containing the metal oxide ion $\left(\mathrm{AB}^{+/-}\right.$in eqn (5)) and a messenger species $\mathrm{M}$, typically a rare gas atom or also an inert molecule. Photodissociation of this complex (scheme (iv) in Fig. 3) can proceed via vibrational predissociation and breaking of the ion-messenger bond:

$$
\mathrm{AB}^{+/-} \mathrm{M} \stackrel{h v}{\rightarrow}\left(\mathrm{AB}^{+/-}\right)^{*} \mathrm{M} \stackrel{\mathrm{IVR}}{\longrightarrow} \mathrm{AB}^{+/-}+\mathrm{M}
$$

Ideally, the perturbation of $\mathrm{AB}^{+}$by $\mathrm{M}$ is small enough that lifetime broadening due to too fast IVR can be neglected and the structural information determined for the complex approximates the structural information of the bare ion well. Typically, the use of He atoms as messenger species approaches this ideal situation the closest. When heavier rare gas atoms like Ar are used, binding energies of more than $1000 \mathrm{~cm}^{-1}$ for cations are not uncommon. ${ }^{62}$ In such cases the perturbation is significant, leading to substantial shifts in vibrational frequencies and changes in the energetic ordering of different isomers with and without rare gas atom(s). Consequently, the rare gas atom needs to be explicitly included in the simulations. Note, IR-PD of messenger-tagged clusters can and often does involve the absorption of more than a single photon.

The best-resolved vibrational spectra up-to-date are obtained by way of IR-PD spectroscopy of metal oxide-rare gas atom complexes. ${ }^{63}$ Especially when light rare gas atoms $(\mathrm{He}, \mathrm{Ne})$ are used, the measured spectra often reflect the linear absorption spectrum quantitatively. ${ }^{64-67}$ Combined with density functional theory (DFT) calculations including powerful global optimization schemes ${ }^{56}$ IR-PD spectra of clusters with up to a few tens of atoms can generally be unambiguously assigned based on a comparison to simulated spectra derived from scaled harmonic frequencies and intensities. An advantage of using ion traps is that the complexes can be directly formed via three-body 
collisions in the buffer-gas filled ion trap, allowing for greater flexibility in the choice of the source conditions. ${ }^{63}$

Rare gas atom tagging: possibilities and limits. As a representative example, IR-PD spectra of rare gas atom tagged binary cerium-vanadium oxide cations ${ }^{66}$ are shown in Fig. 7 and those of cerium oxide cations ${ }^{67}$ in Fig. 8. Compared to the above-described IR-REMPI, IR/UV two-color ionization and IR-MPD spectra, the observed bands in the IR-PD spectra are the most narrow $\left(6-10 \mathrm{~cm}^{-1}\right)$, limited by the spectral bandwidth of the excitation laser as well as dynamical effects. The relative narrowness of the bands combined with a close to linear behavior of the IR-PD cross section (in the measured spectral region) greatly aids in the assignment of geometric structures. For the cerium-vanadium oxide cations satisfactory agreement is exclusively found for the lowest energy structures (see Fig. 7) containing metal atoms in the following

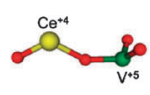

1C

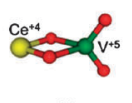

$1 \mathrm{~B}$

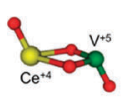

$1 \mathrm{~A}$

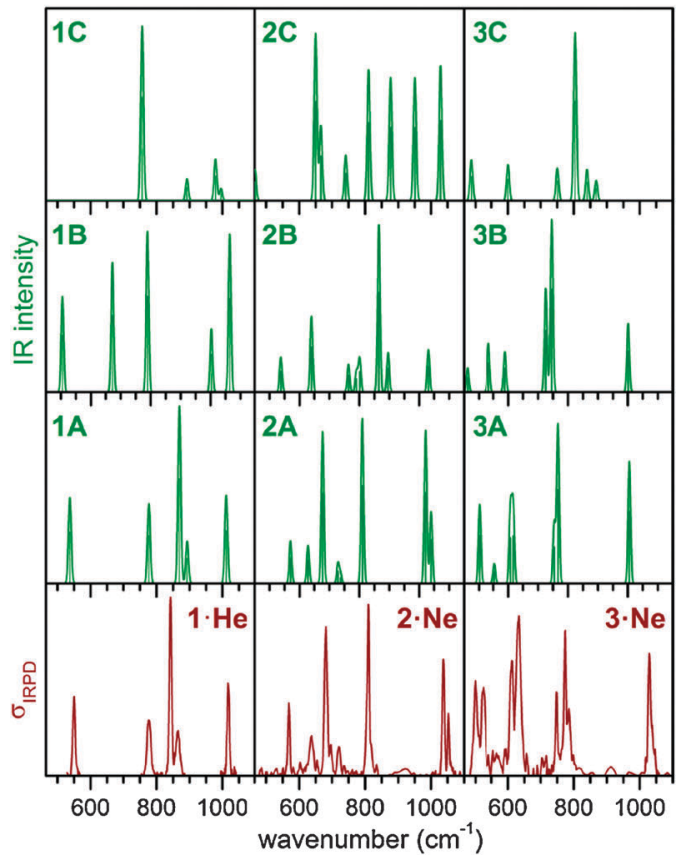

Fig. 7 Optimized structures (top, $\mathrm{O}$ red, $\mathrm{V}$ olive, Ce yellow) of three low-lying isomers $(\mathbf{A}-\mathbf{C})$ of $\mathrm{CeVO}_{4}{ }^{+}(\mathbf{1}), \mathrm{CeV}_{2} \mathrm{O}_{6}{ }^{+}$(2), and $\mathrm{Ce}_{2} \mathrm{VO}_{5}{ }^{+}$ (3), respectively. ${ }^{66}$ The oxidation state of each metal atom is specified. The purple spin density isosurface indicates electron localization on either $\mathrm{Ce}$ or $\mathrm{V}$. Comparison of experimental IR-PD spectra (red traces) of $\mathbf{1} \cdot \mathrm{He}, \mathbf{2} \cdot \mathrm{Ne}$, and $\mathbf{3} \cdot \mathrm{Ne}$ (bottom row) to simulated linear absorption spectra (green traces) of the isomers $\mathbf{1 A - 1 C}, \mathbf{2 A}-\mathbf{2 C}$ and 3A-3C, respectively. ${ }^{66}$

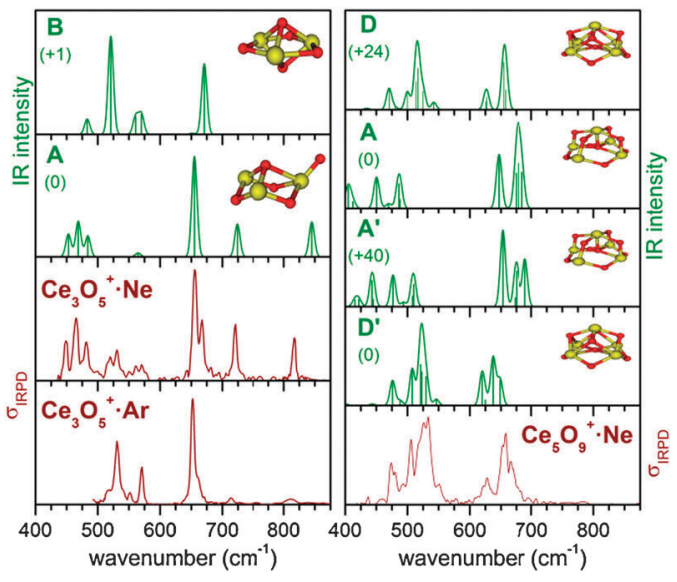

Fig. 8 Simulated linear absorption spectra (green traces, left) and structures of the energetically lowest two isomers, labeled $\mathrm{A}$ and $\mathrm{B}$, of $\mathrm{Ce}_{3} \mathrm{O}_{5}{ }^{+}$and experimental IR-PD spectra of $\mathrm{Ce}_{3} \mathrm{O}_{5}{ }^{+} \cdot \mathrm{Ne}$ and $\mathrm{Ce}_{3} \mathrm{O}_{5}{ }^{+}$. $\mathrm{Ar}$ (red traces, left). ${ }^{67}$ Simulated linear absorption spectra (green traces, right) and structures of two $\mathrm{Ce}_{5} \mathrm{O}_{9}{ }^{+}$isomers, labeled $\mathrm{A}\left(\mathrm{A}^{\prime}\right)$ and $\mathrm{D}\left(\mathrm{D}^{\prime}\right)$, calculated using two DFT functionals, respectively, and the experimental IR-PD spectrum of $\mathrm{Ce}_{5} \mathrm{O}_{9}{ }^{+} \cdot \mathrm{Ne}$ (red trace, right). Relative energies are in $\mathrm{kJ} \mathrm{mol}^{-1}{ }^{67}$

oxidation states: $\mathrm{Ce}^{+4} / \mathrm{V}^{+5}(\mathbf{1 A}), \mathrm{Ce}^{+3} / \mathrm{V}^{+5} / \mathrm{V}^{+5}(\mathbf{2 A})$ and $\mathrm{Ce}^{+3} / \mathrm{Ce}^{+3} / \mathrm{V}^{+5}$ (3A). This confirms the hypothesis that in low coordination, binary $\mathrm{Ce} / \mathrm{V}$ oxide clusters $\mathrm{Ce}$ is always reduced first, ${ }^{66}$ similar to observations for $\mathrm{VO}_{x} / \mathrm{CeO}_{2}(111)$ model catalysts, whose remarkable activity is due to the ability of ceria to easily accommodate electrons in localized f-orbitals. ${ }^{68}$

In some cases differences between the experimental and simulated IR spectra remain. This can have many origins, of which we discuss a few here. First, the correct structure/state may not have been found. An educational example is related to $\mathrm{V}_{2} \mathrm{O}_{5}{ }^{+}$, one of the first metal oxide clusters studied by IR-PD. ${ }^{64}$ Today, powerful global optimization schemes ${ }^{56,69}$ aid the chemical intuition-driven structure searches, greatly reducing the probability of "overlooking" a particularly stable structure. Second, the harmonic approximation used to derive the simulated IR spectrum may break down. See ref. 59 for an example relating to metal oxide clusters. Third, multiple isomers may be present, as is observed, for example, for $\mathrm{Ce}_{3} \mathrm{O}_{5}{ }^{+}$. DFT predicts two isomers, labeled $\mathrm{A}$ and $\mathrm{B}$ in Fig. 8 (left panel), lying within $1 \mathrm{~kJ} \mathrm{~mol}^{-1}$ of each other. ${ }^{67}$ The simulated spectrum of A is reproduced well by the IR-PD spectrum of $\mathrm{Ce}_{3} \mathrm{O}_{5}{ }^{+} \cdot \mathrm{Ne}$, however additional bands are observed in the experimental spectrum, which cannot be explained by A, but can be attributed to B. The experimental proof for the presence of two isomers is found in the IR-PD spectrum of $\mathrm{Ce}_{3} \mathrm{O}_{5}{ }^{+} \cdot \mathrm{Ar}$ (see Fig. 8), which shows similar absorptions, but with different relative intensities $-\mathrm{B}$ is now the dominant species with minor contributions from $\mathrm{A}$. Obviously, the choice of the messenger atom can dramatically influence the relative isomer populations. This is typically due to a higher binding energy of a particular messenger to the energetically higher-lying bare isomer, which can lead to an energetic reordering of the isomers in the presence of the messenger species and consequently to predominant population of the energetically lower-lying messenger-tagged isomer. 
Such a dependence is not unique to $\mathrm{Ce}_{3} \mathrm{O}_{5}{ }^{+}$, but has been observed before and discussed in more detail for other systems like $\mathrm{V}_{3} \mathrm{O}_{7}{ }^{+}, \mathrm{V}_{3} \mathrm{O}_{8}{ }^{+}$or $\mathrm{H}^{+}\left(\mathrm{H}_{2} \mathrm{O}\right)_{6}{ }^{70,71}$ Consequently, it is advisable to perform the calculations on the cluster-rare gas atom complexes, as well as the bare cluster, whenever possible.

Another reason for differences between the experimental IR-PD and simulated DFT-derived spectrum can be inaccuracies related to the DFT functional. One well-documented example is related to the description of the degree of localization of unpaired d-electrons of transition metal atoms. ${ }^{58}$ A similar observation is made for $\mathrm{Ce}_{5} \mathrm{O}_{9}{ }^{+}$(see Fig. 8, right panel). ${ }^{67}$ The prediction of the B3LYP calculations (spectrum A in Fig. 8) is not confirmed by the experiment. Better agreement between the experimental and simulated spectrum is found for isomer $\mathrm{D}$, calculated $24 \mathrm{~kJ} \mathrm{~mol}^{-1}$ above the lowest energy structure. Interestingly, using a different functional, TPSSH instead of B3LYP corrects this discrepancy. The TPSSH calculations find $\mathrm{D}_{\text {(labeled }} \mathrm{D}^{\prime}$ in Fig. 8) as the lowest energy structure and place A (labeled A' in Fig. 8) $40 \mathrm{~kJ} \mathrm{~mol}^{-1}$ higher in energy. Moreover, the simulated IR spectrum of $\mathrm{D}^{\prime}$ shows excellent agreement with the measured IR-PD spectrum of $\mathrm{Ce}_{5} \mathrm{O}_{9}{ }^{+} \cdot \mathrm{Ne}$. The origin of this discrepancy is the overestimation of the degree of localization of the unpaired electron occupying Ce f-states by B3LYP. ${ }^{67}$

Other messenger species: structure-reactivity correlation. While $\mathrm{He}$ and $\mathrm{Ne}$ for cations and $\mathrm{H}_{2}$ for anions are typically the messenger species of choice, the corresponding complexes are often not so readily formed under the given experimental conditions and the use of other inert molecules may be more practical. A recent example is the use of $\mathrm{O}_{2}$ in the study of $(\mathrm{MgO})_{n}{ }^{+}$cations by photodissociation of $(\mathrm{MgO})_{n}{ }^{+} \cdot \mathrm{O}_{2}$ with $n=2-7 .{ }^{49}$ Another example involves propane as a messenger species, which is described in the following paragraphs.

A particularly useful extension of IR-MPD spectroscopy to the study of metal oxide clusters is its combination with reactivity measurements to characterize the structure of reaction intermediates and products. ${ }^{51,52,72}$ The use of a buffer gas filled, temperature controlled ion trap allows studying the reaction of mass-selected ions with neutral reactants under thermalized conditions, as recently demonstrated for the oxidative dehydrogenation (ODH) of propane by $\mathrm{V}_{4} \mathrm{O}_{10}{ }^{+} .{ }^{52}$ From mass spectrometry it is known that upon reaction with propane $\mathrm{ODH}$ is the main reaction channel and involves the transfer of two $\mathrm{H}$ atoms to the cluster, forming $\left[\mathrm{V}_{4} \mathrm{O}_{10} \mathrm{H}_{2}\right]^{+}$concomitant with the elimination of propene. ${ }^{73}$

$\mathrm{V}_{4} \mathrm{O}_{10}{ }^{+}+\mathrm{C}_{3} \mathrm{H}_{8} \rightleftarrows\left(\mathrm{V}_{4} \mathrm{O}_{10} \cdot \mathrm{C}_{3} \mathrm{H}_{8}\right)^{+} \rightarrow\left[\mathrm{V}_{4} \mathrm{O}_{10} \mathrm{H}_{2}\right]^{+}+\mathrm{C}_{3} \mathrm{H}_{6}$

However, a more detailed insight into the molecular level reaction mechanism requires knowledge of the structure of the reaction product $\left[\mathrm{V}_{4} \mathrm{O}_{10} \mathrm{H}_{2}\right]^{+}$. Performing the reaction in excess of propane leads to the formation of a weak product ion-propane complex,

$$
\left[\mathrm{V}_{4} \mathrm{O}_{10} \mathrm{H}_{2}\right]^{+}+\mathrm{C}_{3} \mathrm{H}_{8} \rightleftarrows\left[\mathrm{V}_{4} \mathrm{O}_{10} \mathrm{H}_{2}\right]^{+} \cdot \mathrm{C}_{3} \mathrm{H}_{8},
$$

which can be used to gain structural information on $\left[\mathrm{V}_{4} \mathrm{O}_{10} \mathrm{H}_{2}\right]^{+}$via photodissociation of $\left[\mathrm{V}_{4} \mathrm{O}_{10} \mathrm{H}_{2}\right]^{+} \cdot \mathrm{C}_{3} \mathrm{H}_{8}$.

The IR-MPD spectrum of $\left[\mathrm{V}_{4} \mathrm{O}_{10} \mathrm{H}_{2}\right]^{+} \cdot \mathrm{C}_{3} \mathrm{H}_{8}$ is compared to simulated linear absorption spectra of three possible

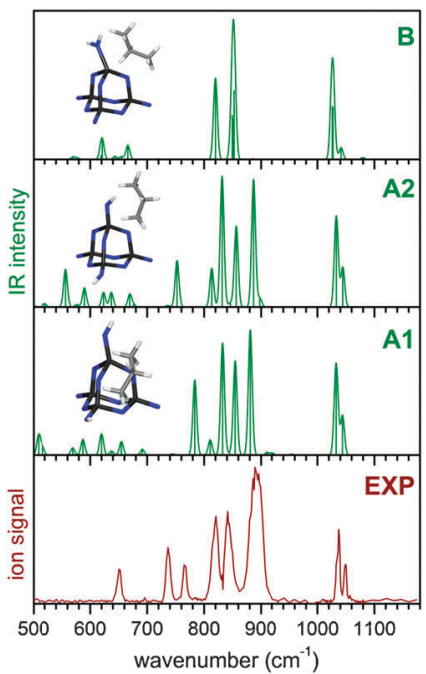

Fig. 9 Experimental IR-MPD spectrum (bottom, red trace) of $\left[\mathrm{V}_{4} \mathrm{O}_{10} \mathrm{H}_{2} \cdot \mathrm{C}_{3} \mathrm{H}_{8}\right]^{+}\left(\mathrm{C}_{3} \mathrm{H}_{8}\right.$ loss channel $)$ after trapping mass-selected $\mathrm{V}_{4} \mathrm{O}_{10}{ }^{+}$ions at $100 \mathrm{~K}$ in the ion trap filled with a $0.002 \%$ propane in a helium gas mixture. Simulated linear IR absorption spectra (green traces) of three structural candidates, labeled B, A1 and A2, are also shown. Adapted from ref. 52, Copyright (2012), with permission from Elsevier.

structural candidates, labeled A1, A2 and B, in Fig. 9. Structures $\mathrm{A}$ and $\mathrm{B}$ differ in the number of vanadyl groups present in the $\left[\mathrm{V}_{4} \mathrm{O}_{10} \mathrm{H}_{2}\right]^{+}$moiety. While structure A contains two vanadyl and two $\mathrm{V}-\mathrm{OH}$ groups, structure $\mathrm{B}$ contains three vanadyl and just a single $\mathrm{V}-\mathrm{OH}_{2}$ group. Structures $\mathrm{A} 1$ and $\mathrm{A} 2$, on the other hand, differ in the way propane physisorbs to the $\left[\mathrm{V}_{4} \mathrm{O}_{10} \mathrm{H}_{2}\right]^{+}$complex. Comparison of the experimental to the simulated spectra clearly favors an assignment to structures $\mathrm{A} 1$ and $\mathrm{A} 2$ rather than B (see Fig. 9). This is in agreement with calculated stabilities of $\mathrm{A} 1$ and $\mathrm{A} 2$, which differ by less than $1 \mathrm{~kJ} \mathrm{~mol}^{-1}$, while $\mathrm{B}$ is $33 \mathrm{~kJ} \mathrm{~mol}^{-1}$ less stable. ${ }^{52}$ Without going into details, the key information gained from the spectroscopic data is that abstraction of the second $\mathrm{H}$-atom forming $\left[\mathrm{V}_{4} \mathrm{O}_{10} \mathrm{H}_{2}\right]^{+}\left(+\mathrm{C}_{3} \mathrm{H}_{6}\right)$ selectively involves two vanadyl groups (structures $\mathrm{A} 1$ and $\mathrm{A} 2$ ) rather than a single one (structure $\mathrm{B}$ ), giving additional weight to the assumption that polymeric (vs. monomeric) vanadyl sites are important in the ODH of alkanes over vanadium oxide catalysts. ${ }^{74}$

\section{Outlook}

While the above examples demonstrate that significant progress has been made in the structure characterization of isolated metal oxide clusters over the last decade, many challenges remain. Concerning IR action spectroscopy, the IR/UV twocolor ionization approach for neutral metal oxide clusters, as well as the IR-PD technique using rare gas atom tagging for mass-selected metal oxide cluster ions, currently represent the most promising approaches, because both, in principle, yield IR spectra that, in combination with the adequate electronic structure calculations, allow for an unambiguous structural assignment for small and medium-sized clusters in many cases. As for the related techniques, discussed at the beginning of this article, MI-IR measurements require a substantial increase in 
sensitivity in order to profit from depositing mass-selected clusters, similar, for example, to MI-UV/VIS studies on massselected metal clusters. ${ }^{75}$ On the other hand, higher resolution variants of conventional APES, like, for example, slow electron velocity map imaging, ${ }^{76}$ are already available and only need to be applied to metal oxide clusters.

The structural characterization for larger sizes - clusters containing more than $\sim 30$ atoms - currently remains, both an experimental as well as a computational challenge. In this size range spectral congestion starts becoming a significant problem, see for example the IR spectrum of $(\mathrm{MgO})_{15}{ }^{+}$in Fig. 5. The relatively high internal temperature of the clusters, $\sim 100 \mathrm{~K}$ in this particular experiment, is one factor contributing to the apparent broadness of the vibrational bands. Significantly lower internal temperatures $(\leq 10 \mathrm{~K})$ can be achieved using closedcycle $\mathrm{He}$ cryostats to cool the neutral clusters. ${ }^{77}$ These are already routinely used to buffer gas cool ions in ion traps. ${ }^{45,78}$ Another intriguing option to reduce the internal energy of the clusters consists in depositing size-selected metal oxide cluster ions inside liquid helium droplets ${ }^{79,80}$ and then measuring a vibrational action spectrum. ${ }^{79,81}$

Almost all experiments up-to-date on the IR action spectroscopy of polynuclear metal oxide clusters have been performed using the intense and widely tunable radiation from IR-FELs. Widely tunable, narrower bandwidth table-top IR lasers have already been applied to studies of many other types of clusters. These lasers will play an increasingly important role in the study of the IR-PD spectroscopy of metal oxide clusters, in particular when the accessible wavelength region is extended to even longer wavelengths $(>16 \mu \mathrm{m})$. For the IR/UV twocolor ionization experiments the combination of radiation from such table-top IR lasers with the widely tunable radiation from third generation synchrotrons can play an important role in advancing this technique, while for the IR-MPD and IR-PD measurements, combining the radiation from these table-top IR lasers with IR-FEL radiation can significantly increase the selectivity and sensitivity of these experiments.

In general, the number of energetically low-lying isomers contributing to an IR spectrum increases with increasing cluster size. For ions, several experimental techniques have been developed to separate isomers. One approach has been described above and involves the systematic variation of the type (or number) of messenger atom(s) in order to study the influence of a change in the relative isomer population on the IR spectrum. This works well for some systems, but is not really generally applicable. Another approach is ion mobility mass spectrometry, ${ }^{82}$ which exploits differences in the shape of the isomers to physically separate them. This method has recently been applied to the study of polyoxometallates for the first time. ${ }^{83}$ Spectroscopically, isomers can also be separated using a recently developed IR/IR double resonance approach. ${ }^{84}$ It will only be a matter of time until these methods are applied systematically to the study of metal oxide cluster ions.

\section{Acknowledgements}

I gratefully acknowledge the contributions from all authors of the original papers and helpful discussions with A. Fielike and G. Meijer. This work was supported by the Collaborative Research Center 546 of the Deutsche Forschungsgemeinschaft.

\section{Notes and references}

1 G. R. Patzke, Y. Zhou, R. Kontic and F. Conrad, Angew. Chem., Int. Ed., 2011, 50, 826-859.

2 N. R. Shiju and V. V. Guliants, Appl. Catal., A, 2009, 356, 1-17.

3 R. Bogue, Sens. Rev., 2009, 29, 310-315.

4 J. Gao, H. Gu and B. Xu, Accts. Chem. Res., 2009, 42, 1097-1107; S. H. Huang and R. S. Juang, J. Nanopart. Res., 2011, 13, 4411-4430.

5 J. Garcia-Barriocanal, A. Rivera-Calzada, M. Varela, Z. Sefrioui, M. R. Diaz-Guillen, K. J. Moreno, J. A. Diaz-Guillen, E. Iborra, A. F. Fuentes, S. J. Pennycook, C. Leon and J. Santarnaria, ChemPhysChem, 2009, 10, 1003-1011.

6 D. K. Böhme and H. Schwarz, Angew. Chem., Int. Ed., 2005, 44, 2336-2354.

7 J. Jortner, in Physics and Chemistry of Finite Systems: From Clusters to Crystals, ed. P. Jena, S. N. Khanna and B. K. Rao, World Scientific, Singapore, 1992, pp. 1-18.

8 H. A. Schwarz, J. Chem. Phys., 1977, 67, 5525-5534; T. Oka, Phys. Rev. Lett., 1980, 45, 531-534.

9 E. J. Bieske and J. P. Maier, Chem. Rev., 1993, 93, 2603-2621; M. A. Duncan, Int. J. Mass Spectrom., 2000, 200, 545-569.

10 Y.-X. Zhao, X.-N. Wu, J.-B. Ma, S.-G. He and X.-L. Ding, Phys. Chem. Chem. Phys., 2011, 13, 1925-1938; J. Roithova and D. Schroeder, Chem. Rev., 2010, 110, 1170-1211; R. A. J. O'Hair and G. N. Khairallah, J. Cluster Sci., 2004, 15, 331-363; K. A. Zemski, D. R. Justes and A. W. Castleman, J. Phys. Chem. B, 2002, 106, 6136-6148; P. B. Armentrout, Annu. Rev. Phys. Chem., 2001, 52, 423-461; G. E. Johnson, R. Mitric, V. BonacicKoutecky and A. W. Castleman, Chem. Phys. Lett., 2009, 475, 1-9; A. W. Castleman, Jr., Catal. Lett., 2011, 141, 1243-1253; S. H. Li, J. Demuth, A. Mirabal, L. Woste and T. Siebert, Phys. Chem. Chem. Phys., 2012, 14, 148-156.

11 K. S. Molek, T. D. Jaeger and M. A. Duncan, J. Chem. Phys., 2005, 123, 144313; E. Kooi and A. W. Castleman Jr., J. Phys. Chem. A, 1999, 103, 5671-5674; K. S. Molek, Z. D. Reed, A. M. Ricks and M. A. Duncan, J. Phys. Chem. A, 2007, 111, 8080-8089; K. S. Molek, C. Anfuso-Cleary and M. A. Duncan, J. Phys. Chem. A, 2008, 112, 9238-9247; Z. A. Reed and M. A. Duncan, J. Phys. Chem. A, 2008, 112, 5354-5362; A. M. Knight, B. Bandyopadhyay, C. L. Anfuso, K. S. Molek and M. A. Duncan, Int. J. Mass Spectrom., 2011, 304, 29-35; M. R. France, J. W. Buchanan, J. C. Robinson, S. H. Pullins, J. L. Tucker, R. B. King and M. A. Duncan, J. Phys. Chem. A, 1997, 101, 6214-6221.

12 Y. Matsuda and E. R. Bernstein, J. Phys. Chem. A, 2005, 109, 314-319; S. G. Sayres, M. W. Ross and A. W. Castleman, J. Chem. Phys., 2011, 135, 054312; M. Foltin, G. J. Stueber and E. R. Bernstein, J. Chem. Phys., 2001, 114, 8971-8989.

13 M. F. Cai, C. C. Carter, T. A. Miller and V. E. Bondybey, J. Chem. Phys., 1991, 95, 73-79.

14 J. M. Merritt, V. E. Bondybey and M. C. Heaven, J. Phys. Chem. $A, 2009,113,13300-13309$.

15 Y. Matsuda and E. R. Bernstein, J. Phys. Chem. A, 2005, 109, 3803-3811.

16 D. Bellert and W. H. Breckenridge, J. Chem. Phys., 2001, 114, 2871-2874; D. Bellert, D. K. Winn and W. H. Breckenridge, Chem. Phys. Lett., 2001, 348, 39-46; D. Bellert, D. K. Winn and W. H. Breckenridge, J. Chem. Phys., 2002, 117, 3139-3148.

17 I. O. Antonov, B. J. Barker and M. C. Heaven, J. Chem. Phys., 2011, 134, 044306.

18 M. Maier-Borst, D. B. Cameron, M. Rokni and J. H. Parks, Phys. Rev. A, 1999, 59, R3162-R3165; D. Schooss, M. N. Blom, J. H. Parks, B. v. Issendorff, H. Haberland and M. M. Kappes, Nano Lett., 2005, 5, 1972-1977.

19 D. E. Cooper, C. M. Klimcak and J. E. Wessel, Phys. Rev. Lett., 1981, 46, 324-328; Y. Inokuchi, O. V. Boyarkin, R. Kusaka, T. Haino, T. Ebata and T. R. Rizzo, J. Am. Chem. Soc., 2011, 133, 12256-12263.

20 L. Andrews and M. Moskovits, Chemistry and Physics of MatrixIsolated Species, North-Holland, Amsterdam, The Netherlands, 1989; I. R. Beattie, Angew. Chem., Int. Ed., 1999, 38, 3294-3306. 
21 V. E. Bondybey, A. M. Smith and J. Agreiter, Chem. Rev., 1996, 96, 2113-2134.

22 J. C. Rivoal, C. Grisolia, J. Lignieres, D. Kreisle, P. Fayet and L. Woste, Z. Phys. D: At., Mol. Clusters, 1989, 12, 481-484.

23 H. Zhendong, S. Bo, Z. Qinwei, S. Deosaran, J. R. Lombardi, D. M. Lindsay and W. Harbich, J. Chem. Phys., 1991, 95, 2206-2209.

24 Y. Gong, M. Zhou and L. Andrews, Chem. Rev., 2009, 109, 6765-6808.

25 I. R. Beattie, J. S. Ogden and D. D. Price, Inorg. Chem., 1978, 17, 3296-3297.

26 C. Herwig and C. Limberg, Inorg. Chem., 2008, 47, 2937-2939.

27 S. F. Vyboishchikov and J. Sauer, J. Phys. Chem. A, 2001, 105, 8588-8598; H.-J. Zhai, J. Döbler, J. Sauer and L.-S. Wang, J. Am. Chem. Soc., 2007, 129, 13270-13276.

28 P. C. Engelking and W. C. Lineberger, J. Chem. Phys., 1977, 66, 5054-5058.

29 H. B. Wu, S. R. Desai and L. S. Wang, J. Am. Chem. Soc., 1996, 118, 5296-5301.

30 H.-J. Zhai and L.-S. Wang, Chem. Phys. Lett., 2010, 500, 185-195.

31 M. Okumura, L. I. Yeh and Y. T. Lee, J. Chem. Phys., 1985, 83, 3705-3706.

32 M. Okumura, L. I. Yeh, J. D. Myers and Y. T. Lee, J. Chem. Phys., 1986, 85, 2328-2329; W. L. Liu and J. M. Lisy, J. Chem. Phys., 1988, 89, 605-606; Y. B. Cao, J. H. Choi, B. M. Haas, M. S. Johnson and M. Okumura, J. Phys. Chem., 1993, 97, 5215-5217; C. G. Bailey, J. Kim, C. E. H. Dessent and M. A. Johnson, Chem. Phys. Lett., 1997, 269, 122-127; M. Gerhards, C. Unterberg and A. Gerlach, Phys. Chem. Chem. Phys., 2002, 4, 5563-5565.

33 K. R. Asmis, A. Fielicke, G. von Helden and G. Meijer, in The Chemical Physics of Solid Surfaces. Atomic Clusters: From Gas Phase to Deposited, ed. D. P. Woodruff, Elsevier, Amsterdam, 2007, vol. 12, pp. 327-375.

34 P. Gruene, J. T. Lyon and A. Fielicke, in Handbook of Nanophysics, ed. K. Sattler, Taylor \& Francis, 2010, vol. 2, pp. 9-14.

35 M. Putter, G. vonHelden and G. Meijer, Chem. Phys. Lett., 1996, 258, 118-122.

36 G. von Helden, D. van Heijnsbergen and G. Meijer, J. Phys. Chem. A, 2003, 107, 1671-1688.

37 G. von Helden, I. Holleman, G. M. H. Knippels, A. F. G van der Meer and G. Meijer, Phys. Rev. Lett., 1997, 79, 5234-5237.

38 J. G. Black, E. Yablonovitch, N. Bloembergen and S. Mukamel, Phys. Rev. Lett., 1977, 38, 1131-1134; V. N. Bagratashvili, V. S. Letokhov, A. A. Makarov and E. A. Ryabov, Multiple Photon Infrared Laser Photophysics and Photochemistry, Harwood Academic Publishers GmbH, Amsterdam, 1985; J. Oomens, A. G. G. M. Tielens, B. Sartakov, G. von Helden and G. Meijer, Astrophys. J., 2003, 591, 968-985.

39 G. von Helden, A. Kirilyuk, D. van Heijnsbergen, B. Sartakov, M. A. Duncan and G. Meijer, Chem. Phys., 2000, 262, 31-39.

40 D. van Heijnsbergen, G. von Helden, G. Meijer and M. A. Duncan, J. Chem. Phys., 2002, 116, 2400-2406.

41 D. van Heijnsbergen, K. Demyk, M. A. Duncan, G. Meijer and G. von Helden, Phys. Chem. Chem. Phys. 2003, 5, 2515-2519.

42 K. Demyk, D. van Heijnsbergen, G. von Helden and G. Meijer, Astron. Astrophys., 2004, 420, 547-552.

43 A. S. Sudbo, P. A. Schulz, D. J. Krajnovich, Y. T. Lee and Y. R. Shen, Opt. Lett., 1979, 4, 219-221.

44 M. Haertelt, A. Fielicke, G. Meijer, K. Kwapien, M. Sierka and J. Sauer, Phys. Chem. Chem. Phys., 2012, 14, 2849-2856.

45 K. R. Asmis, M. Brümmer, C. Kaposta, G. Santambrogio, G. von Helden, G. Meijer, K. Rademann and L. Wöste, Phys Chem. Chem. Phys. 2002, 4, 1101-1104.

46 A. S. Sudbo, P. A. Schulz, Y. R. Shen and Y. T. Lee, in MultiplePhoton Excitation and Dissociation of Polyatomic Molecules, ed. C. D. Cantrell, Springer-Verlag, Berlin, 1986, vol. 35, pp. 95-122.

47 J. Oomens, B. G. Sartakov, G. Meijer and G. von Helden, Int. J. Mass Spectrom., 2006, 254, 1-19.

48 K. R. Asmis and J. Sauer, Mass. Spectrom. Rev., 2007, 26, 542-562; K. R. Asmis and J. Sauer, Mass. Spectrom. Rev., 2008, 27, 205.

49 K. Kwapien, M. Sierka, J. Dobler, J. Sauer, M. Haertelt, A. Fielicke and G. Meijer, Angew. Chem., Int. Ed., 2011, 50, $1716-1719$
50 A. Kirilyuk, A. Fielicke, K. Demyk, G. von Helden, G. Meijer and T. Rasing, Phys. Rev. B: Condens. Matter Mater. Phys., 2010, 82, 020405 .

51 A. Fielicke, R. Mitrić, G. Meijer, V. Bonačić-Koutecký and G. von Helden, J. Am. Chem. Soc., 2003, 125, 15716-15717.

52 T. Wende, J. Döbler, L. Jiang, P. Claes, E. Janssens, P. Lievens, G. Meijer, K. R. Asmis and J. Sauer, Int. J. Mass Spectrom., 2010, 297, 102-106.

53 A. Fielicke, G. Meijer and G. von Helden, J. Am. Chem. Soc., 2003, 125, 3659-3667.

54 A. Fielicke, P. Gruene, M. Haertelt, D. J. Harding and G. Meijer, J. Phys. Chem. A, 2010, 114, 9755-9761.

55 A. Fielicke, G. Meijer and G. von Helden, Eur. Phys. J. D, 2003, 24, 69-72.

56 M. Sierka, J. Döbler, J. Sauer, G. Santambrogio, M. Brümmer, L. Wöste, E. Janssens, G. Meijer and K. R. Asmis, Angew. Chem., Int. Ed., 2007, 46, 3372-3375.

57 E. Janssens, G. Santambrogio, M. Brümmer, L. Wöste, P. Lievens, J. Sauer, G. Meijer and K. R. Asmis, Phys. Rev. Lett., 2006, 96, 233401.

58 K. R. Asmis, G. Santambrogio, M. Brümmer and J. Sauer, Angew. Chem., Int. Ed., 2005, 44, 3122-3125.

59 G. Santambrogio, M. Brümmer, L. Wöste, J. Döbler, M. Sierka, J. Sauer, G. Meijer and K. R. Asmis, Phys. Chem. Chem. Phys., 2008, 10, 3992-4005.

60 S. Feyel, H. Schwarz, D. Schröder, C. Daniel, H. Hartl, J. Döbler, J. Sauer, G. Santambrogio, L. Wöste and K. R. Asmis, ChemPhysChem, 2007, 8, 1640-1647.

61 A. P. Woodham, G. Meijer and A. Fielicke, Angew. Chem., Int. Ed., 2012, DOI: 10.1002/anie.201108958.

62 D. Bellert and W. H. Breckenridge, Chem. Rev., 2002, 102, $1595-1622$.

63 M. Brümmer, C. Kaposta, G. Santambrogio and K. R. Asmis, J. Chem. Phys., 2003, 119, 12700-12703.

64 K. R. Asmis, G. Meijer, M. Brümmer, C. Kaposta, G. Santambrogio, L. Wöste and J. Sauer, J. Chem. Phys., 2004, 120, 6461-6470.

65 G. Santambrogio, E. Janssens, S. Li, T. Siebert, G. Meijer, K. R. Asmis, J. Döbler, M. Sierka and J. Sauer, J. Am. Ceram. Soc., 2008, 130, 15143-15149.

66 L. Jiang, T. Wende, P. Claes, S. Bhattacharyya, M. Sierka, G. Meijer, P. Lievens, J. Sauer and K. R. Asmis, J. Phys. Chem. A, 2011, 115, 11187-11192.

67 A. M. Burow, T. Wende, M. Sierka, R. Wlodarczyk, J. Sauer, P. Claes, L. Jiang, G. Meijer, P. Lievens and K. R. Asmis, Phys. Chem. Chem. Phys. 2011, 13, 19393-19400.

68 M. V. Ganduglia-Pirovano, C. Popa, J. Sauer, H. Abbott, A. Uhl, M. Baron, D. Stacchiola, O. Bondarchuk, S. Shaikhutdinov and H. J. Freund, J. Am. Chem. Soc., 2010, 132, 2345-2349.

69 D. M. Deaven and K. M. Ho, Phys. Rev. Lett., 1995, 75, 288-291.

70 K. Mizuse and A. Fujii, Phys. Chem. Chem. Phys., 2011, 13, 7098-7104.

71 K. R. Asmis, T. Wende, M. Brümmer, O. Gause, G. Santambrogio, C. Kaposta, J. Döbler, A. Niedziela and J. Sauer, Phys. Chem. Chem. Phys., 2012, DOI: 10.1039/c1032cp40245a.

72 G. Altinay, M. Citir and R. B. Metz, J. Phys. Chem. A, 2010, 114, 5104-5112; G. Altinay and R. B. Metz, J. Am. Soc. Mass Spectrom., 2010, 21, 750-757; G. Altinay, A. Kocak, J. S. Daluz and R. B. Metz, J. Chem. Phys., 2011, 135, 084311; N. A. Moore, R. Mitrić, D. R. Justes, V. Bonačić-Koutecký and A. W. Castleman, J. Phys. Chem. B, 2006, 110, 3015-3022.

73 S. Feyel, D. Schröder and H. Schwarz, J. Phys. Chem. A, 2006 110, 2647-2654.

74 M. Cavalleri, K. Hermann, A. Knop-Gericke, M. Havecker, R. Herbert, C. Hess, A. Oestereich, J. Dobler and R. Schlogl, J. Catal., 2009, 262, 215-223.

75 C. Felix, C. Sieber, W. Harbich, J. Buttet, I. Rabin, W. Schulze and G. Ertl, Chem. Phys. Lett., 1999, 313, 105-109; F. Conus, J. T. Lau, V. Rodrigues and C. Felix, Rev. Sci. Instrum., 2006, 77, 113103

76 D. M. Neumark, J. Phys. Chem. A, 2008, 112, 13287-13301.

77 R. Moro, X. S. Xu, S. Y. Yin and W. A. de Heer, Science, 2003, 300, 1265-1269.

78 D. Gerlich, Phys. Scr., 1995, T59, 256-263; H. Hess, S. Kwiet, L. Socaciu, S. Wolf, T. Leisner and L. Wöste, Appl. Phys. B: Lasers Opt., 2000, 71, 337-341. 
79 S. Smolarek, N. B. Brauer, W. J. Buma and M. Drabbels, J. Am. Chem. Soc., 2010, 132, 14086-14091.

80 F. Bierau, P. Kupser, G. Meijer and G. von Helden, Phys. Rev. Lett., 2010, 105, 133402.

81 X. Zhang, N. B. Brauer, G. Berden, A. M. Rijs and M. Drabbels, J. Chem. Phys., 2012, 136, 044305.

82 G. Von Helden, M. T. Hsu, P. R. Kemper and M. T. Bowers, J. Chem. Phys., 1991, 95, 3835-3837.

83 J. Thiel, D. Yang, M. H. Rosnes, X. Liu, C. Yvon, S. E. Kelly, Y.-F. Song, D.-L. Long and L. Cronin, Angew. Chem., Int. Ed., 2011, 50, 8871-8875.

84 B. M. Elliott, R. A. Relph, J. R. Roscioli, J. C. Bopp, G. H. Gardenier, T. L. Guasco and M. A. Johnson, J. Chem. Phys., 2008, 129, 094303.

85 B. Tremblay, P. Roy, L. Manceron, P. Pullumbi, Y. Bouteiller and D. Roy, J. Chem. Phys., 1995, 103, 1284-1291.

86 L. Andrews, G. V. Chertihin, C. A. Thompson, J. Dillon, S. Byrne and C. W. Bauschlicher, J. Phys. Chem., 1996, 100, 10088-10099.

87 M. Gutowski, P. Skurski, X. Li and L. S. Wang, Phys. Rev. Lett., 2000, 85, 3145-3148.

88 S. R. Desai, H. B. Wu, C. M. Rohlfing and L. S. Wang, J. Chem. Phys., 1997, 106, 1309-1317; H. Wu, X. Li, X.-B. Wang, C.-F. Ding and L.-S. Wang, J. Chem. Phys., 1998, 109, 449-458; M. Sierka, J. Dobler, J. Sauer, H. J. Zhai and L. S. Wang, ChemPhysChem, 2009, 10, 2410-2413.

89 G. V. Chertihin and L. Andrews, J. Chem. Phys., 1996, 105, 2561-2574.

90 G. V. Chertihin, L. Andrews, M. Rosi and C. W. Bauschlicher, J. Phys. Chem. A, 1997, 101, 9085-9091.

91 Y. X. Zhao, J. Y. Yuan, X. L. Ding, S. G. He and W. J. Zheng, Phys. Chem. Chem. Phys., 2011, 13, 10084-10090.

92 L. Andrews, M. F. Zhou, G. V. Chertihin and C. W. Bauschlicher, J. Phys. Chem. A, 1999, 103, 6525-6532.

93 A. Pramann, Y. Nakamura, A. Nakajima and K. Kaya, J. Phys. Chem. A, 2001, 105, 7534-7540.

94 Y. Gong, Q. Zhang and M. Zhou, J. Phys. Chem. A, 2007, 111, 3534-3539.

95 H. B. Wu and L. S. Wang, J. Chem. Phys., 1997, 107, 8221-8228; H. J. Zhai and L. S. Wang, J. Am. Chem. Soc., 2007, 129, 3022-3026.

96 M. Li, S. R. Liu and P. B. Armentrout, J. Chem. Phys., 2009, 131, 1443101-1443115.

97 G. V. Chertihin, W. D. Bare and L. Andrews, J. Phys. Chem. A, 1997, 101, 5090-5096.

98 A. Pramann, K. Koyasu, A. Nakajima and K. Kaya, J. Chem. Phys., 2002, 116, 6521-6528; H. J. Zhai and L.-S. Wang, J. Chem. Phys., 2002, 117, 7882-7888.

99 H.-J. Zhai, J. Döbler, J. Sauer and L.-S. Wang, J. Am. Chem. Soc., 2007, 129, 13270-13276.

100 H. J. Zhai, X. H. Zhang, W. J. Chen, X. Huang and L. S. Wang, J. Am. Chem. Soc., 2011, 133, 3085-3094.

101 J. E. Mann, S. E. Waller, D. W. Rothgeb and C. C. Jarrold, J. Chem. Phys., 2011, 135, 104317; H. J. Zhai, B. Wang, X. Huang and L. S. Wang, J. Phys. Chem. A, 2009, 113, 3866-3875; W.-J. Chen, H.-J. Zhai, Y.-F. Zhang, X. Huang and L.-S. Wang, J. Phys. Chem. A, 2010, 114, 5958-5966.

102 H.-J. Zhai, B. B. Averkiev, D. Y. Zubarev, L.-S. Wang and A. I. Boldyrev, Angew. Chem., Int. Ed., 2007, 46, 4277-4280; H. J. Zhai, B. Wang, X. Huang and L. S. Wang, J. Phys. Chem. A, 2009, 113, 9804-9813.

103 G. V. Chertihin, W. D. Bare and L. Andrews, J. Chem. Phys., 1997, 107, 2798-2806; Q. Zhang, Y. Zhao, Y. Gong and M. Zhou, J. Phys. Chem. A, 2007, 111, 9775-9780.

104 H.-J. Zhai, X. Huang, T. Waters, X.-B. Wang, R. A. J. O'Hair, A. G. Wedd and L.-S. Wang, J. Phys. Chem. A, 2005, 109, 10512-10520.

105 H.-J. Zhai and L.-S. Wang, J. Chem. Phys., 2006, 125, 164315; H.-J. Zhai, S. Li, D. A. Dixon and L.-S. Wang, J. Am. Chem. Soc., 2008, 130, 5167-5177.
106 S. Li, H.-J. Zhai, L.-S. Wang and D. A. Dixon, J. Phys. Chem. A, 2009, 113, 11273-11288.

107 K. R. Asmis, T. Wende, E. Janssens, P. Claes and P. Lievens, personal communication.

108 X. Yang, T. Waters, X. B. Wang, R. A. J. O'Hair, A. G. Wedd, J. Li, D. A. Dixon and L. S. Wang, J. Phys. Chem. A, 2004, 108, 10089-10093; X. Huang, H. J. Zhai, B. Kiran and L. S. Wang, Angew. Chem., Int. Ed., 2005, 44, 7251-7254; D. W. Rothgeb, J. E. Mann, S. E. Waller and C. C. Jarrold, J. Chem. Phys., 2011, 135, 104312.

109 B. L. Yoder, J. T. Maze, K. Raghavachari and C. C. Jarrold, J. Chem. Phys., 2005, 122, 094313.

110 N. J. Mayhall, D. W. Rothgeb, E. Hossain, K. Raghavachari and C. C. Jarrold, J. Chem. Phys., 2009, 130, 124313; D. W. Rothgeb, E. Hossain, A. T. Kuo, J. L. Troyer and C. C. Jarrold, J. Chem. Phys., 2009, 131, 044310.

111 D. Stolcic, Y. D. Kim and G. Gantefor, J. Chem. Phys., 2004, 120, 5-7; H. J. Zhai, X. Huang, L. F. Cui, X. Li, J. Li and L. S. Wang, J. Phys. Chem. A, 2005, 109, 6019-6030; X. Huang, H. J. Zhai, J. Li and L. S. Wang, J. Phys. Chem. A, 2006, 110, 85-92; X. Huang, H. J. Zhai, T. Waters, J. Li and L. S. Wang, Angew. Chem., Int. Ed., 2006, 45, 657-660.

112 G. V. Chertihin and L. Andrews, J. Phys. Chem. A, 1997, 101, 8547-8553; Y. Gong, G. Wang and M. Zhou, J. Phys. Chem. A, 2008, 112, 4936-4941.

113 S. N. Khanna, P. Jena, W. J. Zheng, J. M. Nilles and K. H. Bowen, Phys. Rev. B: Condens. Matter Mater. Phys., 2004, 69, 144418; N. O. Jones, S. N. Khanna, T. Baruah, M. R. Pederson, W. J. Zheng, J. M. Nilles and K. H. Bowen, Phys. Rev. B: Condens. Matter Mater. Phys., 2004, 70, 134422.

114 H.-J. Zhai, W. J. Chen, X. Huang and L.-S. Wang, RSC Adv. 2012, DOI: $10.1039 / \mathrm{c} 1032 \mathrm{ra} 00753 \mathrm{c}$.

115 G. V. Chertihin, W. Saffel, J. T. Yustein, L. Andrews, M. Neurock, A. Ricca and C. W. Bauschlicher, J. Phys. Chem., 1996, 100, 5261-5273.

116 L. S. Wang, J. W. Fan and L. Lou, Surf. Rev. Lett., 1996, 3 , 695-699; G. L. Gutsev, C. W. Bauschlicher, H. J. Zhai and L. S. Wang, J. Chem. Phys., 2003, 119, 11135-11145.

117 G. V. Chertihin, A. Citra, L. Andrews and C. W. Bauschlicher, J. Phys. Chem. A, 1997, 101, 8793-8802; D. Danset and L. Manceron, Phys. Chem. Chem. Phys., 2005, 7, 583-591; S. O. Souvi, D. Danset, M. E. Alikhani and L. Manceron, J. Phys. Chem. A, 2010, 114, 11399-11407.

118 A. Pramann, K. Koyasu, A. Nakajima and K. Kaya, J. Phys. Chem. A, 2002, 106, 4891-4896; R. Z. Li, H. G. Xu, G. J. Cao, Y. C. Zhao and W. J. Zheng, J. Chem. Phys., 2011, 135, 134307.

119 A. Citra, G. V. Chertihin, L. Andrews and M. Neurock, J. Phys. Chem. A, 1997, 101, 3109-3118; F. Allouti, L. Manceron and M. E. Alikhani, Phys. Chem. Chem. Phys., 2006, 8, 3715-3725.

120 R. Yang, Y. Gong and M. Zhou, Chem. Phys., 2007, 340, 134-140.

121 G. V. Chertihin, L. Andrews and C. W. Bauschlicher, J. Phys. Chem. A, 1997, 101, 4026-4034.

122 L. S. Wang, H. B. Wu, S. R. Desai and L. Lou, Phys. Rev. B Condens. Matter Mater. Phys., 1996, 53, 8028-8031; F. von GynzRekowski, N. Bertram, G. Gantefor and Y. D. Kim, J. Phys. Chem. B, 2004, 108, 18916-18918.

123 H. J. Zhai, C. Burgel, V. Bonacic-Koutecky and L. S. Wang, J. Am. Chem. Soc., 2008, 130, 9156-9167; W. Huang, H.-J. Zhai and L.-S. Wang, J. Am. Chem. Soc., 2010, 132, 4344-4351.

124 Z. Zeng-Guang, X. Hong-Guang, Z. Yuchao and Z. Weijun, J. Chem. Phys., 2010, 133, 154314; Z. G. Zhang, H. G. Xu, X. Y. Kong and W. J. Zheng, J. Phys. Chem. A, 2011, 115, 13-18.

125 T. Waters, X. Huang, X.-B. Wang, H.-K. Woo, R. A. J. O'Hair, A. G. Wedd and L.-S. Wang, J. Phys. Chem. A, 2006, 110, 10737-10741.

126 J. E. Mann, D. W. Rothgeb, S. E. Waller and C. C. Jarrold, J. Phys. Chem. A, 2010, 114, 11312-11321.

127 C. C. Arnold, personal communication. 